Cadernos de Filosofia Alemã 2, Р. 35-55, 1997

\title{
Quem possui a filosofia?
}

\author{
Paulo Licht dos Santos*
}

Resumo: Este estudo se ocupa da Declaração sobre a doutrina da ciência de Fichte, crítica de Kant a Fichte publicada em 1799. Inicialmente são apresentados alguns dados bibliográficos da relação entre "o mestre e seus discípulos" (particularmente Fichte). Além da biografia, indica-se algumas razões doutrinais que levam Kant a atacar a doutrina da ciência de Fichte, bem como a defender a Crítica da razão pura contra a interpretação de seus discípulos. Finalmente, a natureza da questão, que põe lado a lado a filosofia de Kant e a de Fichte, nos leva a algumas questões sobre a pertinência da abordagem utilizada por alguns historiadores de filosofia no estudo da relação entre as duas filosofias.

Palavras-chave: lógica pura - propedêutica - sistema - filosofia transcendental - doutrina da ciência

Ele parece nem mesmo compreender aquilo de que propriamente se trata na investigação com que me ocupei (...); e seja por impaciência em refletir sobre uma obra tão vasta, seja por humor sombrio relativamente a uma reforma iminente de uma ciência na qual ele acreditava estar tudo a limpo já há muito, ou, ainda, (...) por real estreiteza de concepção, responsável por ele nunca ultrapassar pelo pensamento a sua metafísica de escola, numa palavra, ele percorre com impetuosidade uma longa série de proposições sem conhecer suas premissas. (Kant)

Com a Declaração sobre a doutrina da ciência de Fichte**, Kant marca a sua ruptura definitiva com Fichte. Em primeiro lugar, ruptura filosófica: sem meias palavras, Kant diz ser a doutrina da ciência de Fichte "um sistema inteiramente insustentável". Mas o que em princípio poderia exprimir apenas uma

\footnotetext{
* Mestrando do Departamento de Filosofia - FFLCH-USP.

** Esse texto se encontra traduzido às p. 57-60 deste número dos Cadernos de Filosofia Alemã.
} 
divergência, profunda, mas meramente no plano da especulação, é também um ataque pessoal: além dos amigos cuja boa intenção se apaga no resultado prejudicial, há também, diz Kant, os amigos "fraudulentos e ardilosos". Em qual das categorias, pouco abonadoras, estaria Fichte? A Declaração é o desenlace de uma relação que começara auspiciosamente nove anos antes e, a partir de certo momento, marcaria de forma indelével não só o percurso de Fichte, claro, mas também o percurso pessoal e filosófico de Kant (suas cartas e o Opus postumum testemunham isso $)^{1}$. É em 1790 que Fichte, ao freqüentar um curso obrigatório sobre as três Críticas, toma conhecimento da filosofia kantiana. Entusiasmado sobretudo com a doutrina kantiana da liberdade e da autonomia moral, dirige-se em 1791 a Königsberg para conhecer pessoalmente aquele homem "honrado em toda a Europa, mas que certamente poucas pessoas em toda a Europa amam tanto quanto eu" (carta a Kant, 18.08.1791). Fichte chega a Königsberg em $1^{0}$ o de julho e em sua primeira visita, de 3 dias, não é recebido pelo mestre de modo especial. Fichte também se decepciona com a preleção de Kant: "suas aulas não são tão úteis como seus escritos". Seis semanas depois, envia a Kant o manuscrito Ensaio de uma crítica a toda revelação, como carta de apresentação. Kant tem uma impressão favorável do livro e procura apresentar Fichte ao círculo de amigos e intelectuais de Königsberg. Depois de alguns dias, Fichte, vendo-se sem dinheiro, pede a Kant que lhe custeie a viagem de retorno. Para evitar o constrangimento de um empréstimo, Kant faz chegar à mão de um editor o manuscrito de Fichte, e consegue para seu admirador o cargo de preceptor junto a uma família, perto de Danzig. O escrito de Fichte é então publicado em 1792 e, intencionalmente ou não, aparece sem o nome do autor, o que vem a ser altamente favorável a Fichte, pois em razão do título, do local da editora e de sua tendência geral, o livro foi logo tomado como uma obra de Kant, mesmo pelos especialistas. Quando pouco mais tarde Kant esclarece o caso, Fichte de um só golpe torna-se conhecido, é chamado a ser colaborador da Gazeta Literária e sucessor de Reinhold na Universidade de Iena. Não demora muito para que comece o distanciamento filosófico, sem que no entanto a relação pessoal sofra algum prejuízo. Fichte, ao enviar a Kant, em 1794, um exemplar de algumas preleções do seu Sobre o conceito da doutrina da ciência, ou da assim chamada filosofia, ainda se descreve como um discípulo ante o mestre: "À parte o fato de que o aceno do mestre para o discípulo tem de ser infinitamente importante e que o juízo que o senhor proferir irá guiar, corrigir e impulsionar meus passos, talvez não seja de pouca importância para o progresso da própria ciência, se esse juízo vier a ser conhecido" (carta de Fichte a Kant, 
6.10.1794). Mas, já nesse ano, os kantianos "ortodoxos" vêm a campo, nos Anais de Jacob, para criticar o autor da Doutrina da ciência, quando também chegam aos ouvidos de Fichte juízos depreciativos da parte de Kant. Minguase igualmente a troca de cartas entre eles. Apesar disso, no verão de 1796, Fichte ainda homenageia o mestre: dá ao único filho, então nascido, o nome de Immanuel. No final de 1797, dirigindo-se ao "caríssimo amigo", Kant desculpa-se pelo longo silêncio, que atribui ao estado de saúde e à fraqueza da idade avançada. Talvez como que se desculpando também por não ter se ocupado com os trabalhos que Fichte lhe mandara anteriormente, Kant escreve: "de bom grado deixo aos outros a sutileza da especulação teórica, sobretudo quando diz respeito aos seus novos apices, por demais agudos"; no entanto, Kant compromete-se a ser mais diligente com "as cartas e notícias literárias" de Fichte: "sobretudo porque vi em seus novos trabalhos ${ }^{2}$ desenvolver-se o primoroso talento de uma exposição viva e unida à popularidade, uma vez que o senhor já percorreu o espinhoso caminho da escolástica e não achará necessário voltar a ele" (na Declaração, esses trechos são reproduzidos, não muito fielmente, por Kant). Logo em seguida, em 1.01.1798, Fichte replica ao "prezado amigo e professor": "não penso ainda em dar adeus à escolástica. Pratico-a com vontade e leveza, e ela intensifica e eleva minha força" (Kant também reproduz na Declaração, com alguma modificação, essas palavras de Fichte). Pelo que sabemos, são as duas últimas cartas que os dois filósofos trocam.

Fichte não é, sabidamente, um caso isolado. Também outros discípulos de Kant deixam para trás o entusiasmo inicial e se afastam do mestre, menos com a intenção de seguirem um caminho próprio do que com o intuito de levar adiante o caminho aberto pela filosofia crítica. O rompimento com Fichte é apenas o último e mais explosivo. O primeiro caso foi Maimon. É digno de nota que a discordância com esse "seu aluno" (assim Maimon assina em carta a Kant, jul.1789) acabe também por extravasar em outro plano que o filosófico, a exemplo do que acontece anos mais tarde com Fichte. Sobre Maimon, Kant tem no início uma opinião bem favorável: "nenhum de meus adversários entendeu tão bem a mim e à questão capital, e somente poucos poderiam possuir tanta argúcia para tais investigações profundas como o senhor Maimon" (carta a Marcus Herz, 26.05.1789). No entanto, com o passar do tempo a situação muda. Cinco anos depois, escreve um Kant politicamente incorreto (diriam hoje): o que "Maimon quer propriamente com a sua retificação da filosofia crítica (de bom grado os judeus tentam semelhantes coisas, para se darem ares de importância à custa de outros) jamais pude compreender direito e tenho de 
deixar a outros que o corrijam (a Reinhold, 28.03.1794). Ao contrário do que aconteceu com Maimon, que jamais foi pessoalmente próximo a Kant, o afastamento de Reinhold foi mais doloroso, observa Vorländer. De divulgador da obra de Kant, Reinhold passa a reclamar que Kant preferia outros que fossem seu eco. E Kant, que ainda em maio de 1793 chama Reinhold "caríssimo amigo", não sem alguma ironia se refere a ele e a Fichte, em 1797, como "amigos hipercríticos" (a Tieftrunk, 13.10.1997). Logo se mostra que é a sombra de Fichte que se interpõe entre Kant e Reinhold: "Ouço, escreve Kant, que Reinhold, que abriu mão de seus princípios por Fichte, mudou há pouco de opinião e se reconverteu. Assistirei tranqüilo a esse jogo e deixo que o mundo mais jovem e vigoroso, que não se deixa enganar por tais produtos efêmeros, determine o valor deles" (a Kiesewetter, 19.10.1798). Um curso mais amistoso seguiu a disputa com Beck, talvez porque este, querendo apenas explicar o trabalho de Kant, jamais tenha pretendido "ensinar algo de novo" (a Kant, 20.06.1797) com o seu Único ponto de vista possível do qual a filosofia crítica tem de ser julgada (1796). Mas é Fichte que parece mais uma vez assombrar sua relação com Kant. Beck, como que para exorcizar o fantasma e não provocar o despeito do mestre, sente uma forte necessidade de se afirmar distante da bête noire: "Asseguro-lhe, enquanto for um homem honrado, que me encontro infinitamente distante desse absurdo fichtiano. (...) Mas eu sei que o senhor Fichte, que, como parece, procura adeptos, diz de mim que ele e eu nos encontramos no mesmo caminho, por mais que (...) eu tenha dito o contrário. Quando o encontrei no último feriado de Páscoa em Iena, ele realmente quis me encantar dessa maneira. Começou de fato uma conversa comigo: 'Sei que o senhor tem a mesma opinião que eu: que o entendimento faz a coisa'. Disse-me algumas asneiras, e talvez ninguém jamais, com respostas amistosas, o tenha transtornado tanto quanto eu, assim que o perscrutei" (a Kant, 24.07.1797). No entanto, embora discorde e espere que Beck corrija o ponto de vista, Kant põe a amizade acima das disputas filosóficas: quer manter "o amor e respeito para com o senhor Beck", pois "o que devem ser para nós todas as elaborações e conflitos da especulação se a bondade do coração paga por isso?" (a Tieftrunk, 12.07.1797).

Se com Maimon há indiferença, com Reinhold, a altivez diante do juízo público e com Beck, a amizade acima da filosofia - o que teria levado Kant a fazer publicamente uma declaração contra a filosofia de Fichte e, perdendo a "bondade do coração", atacar os amigos de um modo indiscriminado e áspero? A ocasião é certamente propiciada pelo convite público na Gazeta Literária de 
Erlangen. A causa possível é, conjectura Vorländer, a influência negativa sobre Kant de Johann Schulz e de outros kantianos de "estrita observância". A causa um pouco mais distante no tempo, dois anos antes, mas talvez não menos decisiva, está na polêmica de Kant com o fisiocrata alemão Johann Schlettwein. Essa polêmica, também tornada pública, talvez explique um dos aspectos da Declaração. Numa carta de 11 de maio de 1797, publicada depois nas Berlinische Blätter de setembro do mesmo ano, Schlettwein lança um "desafio literário" ao filósofo de Königsberg. Entre outras coisas, diz que os escritos de Kant são plenos "da mais orgulhosa pretensão de uma superioridade do poder intelectual [de Kant] sobre o dos outros homens, de todos os tempos (...). Seu orgulho, caro Kant, verdadeiramente supera tudo o que até agora se chamava orgulho intelectual". Diz também que Kant é o maior culpado pelo "escândalo" da guerra que cada filósofo crítico trava para se impor sobre os demais como o legítimo intérprete do "sentido e espírito" dos escritos kantianos, já que "o senhor não vem a público proclamar claramente quais destes escritores realmente o compreenderam e quais não: Reinhold, Fichte, Beck ou seja lá quem for". Em meio a essas acusações, Schlettwein trata Kant por "meu caríssimo", "meu querido Kant", "meu estimadíssimo e fraternalmente amado Kant", "meu querido e velho irmão Kant" e, finalmente, na réplica a Kant, assina: "honrado irmão e amigo, Schlettwein". Não teria Kant em mente esse episódio, e não Fichte, quando na Declaração se refere aos "amigos fraudulentos e ardilosos" que escondem suas armadilhas sob uma linguagem benfazeja? Mas o que há de propriamente importante é que o "desafio" extrai de Kant uma tomada de posição quanto ao intérprete crítico autorizado. Note-se que essa tomada de posição não é válida absolutamente, mas segundo os termos propostos por Schlettwein: quem teria melhor compreendido os pontos principais dos escritos de Kant, como este os quer saber compreendidos. Kant, na resposta publicada no mesmo número das Berlinische Blätter, destaca com negrito essa restrição, fazendo-nos ver que dá uma resposta parcial e interessada, e não a de um juiz que não faz parte do litígio. Isso não é senão um modo oblíquo e às avessas de dizer o que escrevera antes a Kiesewetter sobre Reinhold: "Assistirei tranqüilo a esse jogo e deixo que o mundo mais jovem e vigoroso, que não se deixa enganar por tais produtos efêmeros, determine o valor deles". Kant, sem deixar de registrar o "estranho tom" de Schlettwein, diz que quem realmente o compreende é, "sem dúvida", Schulz, pastor e professor de matemática de Königsberg. Na tomada de posição, vale notar a cláusula restritiva: "Aqui somente estipulo aceitar que me refiro às suas palavras (as do senhor pastor) segundo a letra, não segun- 
do um pretenso espírito aí subjacente (pois então se pode introduzir o que se quiser)"; (mais tarde, na Declaração, Kant vai aplicar essa cláusula à sua própria obra). A resposta pública a Schlettwein certamente tornaria desnecessária a Declaração de 1799, não permanecesse ainda o "escândalo" do conflito em torno do legítimo continuador de Kant. Assim, Garve (nas palavras de Goethe, "um dos mais proeminentes filósofos de nosso tempo, juntamente com Kant, Mendelssohn e Sulzer") escreve a Kant um ano depois da disputa com Schlettwein: "Gostaria também de saber o que o senhor pensa sobre os novos progressos que alguns de seus discípulos, especialmente Fichte, acreditam ter feito na filosofia desde o aparecimento da Crítica" (setembro de 1798). Kant, em sua resposta a Garve, em 21.09.1798, não diz uma única palavra sobre Fichte e menciona que no momento se ocupa com a "Passagem dos princípios metafísicos da natureza para a física"; para um muitíssimo bom entendedor, essas palavras bastariam para determinar como Kant concebia "os novos progressos na filosofia desde o aparecimento da Crítica" e, por conseqüência, o que achava do projeto fichtiano. Esse quadro torna patente a pressão que existe de todos os lados sobre Kant para que marque posição quanto ao criador da Doutrina da ciência.

No entanto, além dos motivos exteriores, há também um interesse próprio de Kant. É bastante significativo que, em 1799, quando enfim vai a público, Kant já não mostre aquele traço da nobre atitude para com Beck: a amizade acima da polêmica filosófica. Sinal talvez de que a Declaração tenha sido apenas um lapsus calami num momento de mau humor. Antes da Declaração, Pörschke já havia observado a Fichte: "com certeza, ele [Kant] é um modelo de escritor humilde; com freqüência o ouço julgar nobremente seus adversários, que só não devem atacá-lo pessoalmente, ou tratá-lo como se fosse um monge, pois então ele se torna amargo" (Kant 5, v. 12, p. 545). Explicação análoga nos dá Vleeschauwer: a Declaração seria o gesto de revolta de alguém cujo amor próprio teria sido ferido pela acusação de ter deixado inacabada a sua obra, pela pretensão de Fichte e, finalmente, pela reação de um público que, tendo se desafeiçoado do criticismo ortodoxo, promovera os discípulos a corifeus da filosofia transcendental (cf. Vleeschauewr 11, p. 546). Mas a Declaração, com todo seu destempero, não é apenas sinal de uma reação momentânea, que desabaria com uma intensidade proporcional à magnitude de Fichte, a maior figura na guerra acirrada entre os continuadores de Kant; é também, e principalmente, sinal de que Kant sentia ameaçado o criticismo como um todo. Afinal, a "escandalosa" disputa entre os discípulos tocava em um ponto sensível do projeto 
kantiano. Como Schlettwein, apesar de suas leviandades, já apontara antes a Kant com precisão, é a própria Crítica da razão pura (CRP), em seu "Prefácio" da segunda edição, que diz: "Se a elaboração dos conhecimentos que pertencem aos negócios da razão segue ou não a via segura da ciência, isso logo se pode julgar pelo resultado; (...) se não é possível que os diferentes colaboradores alcancem unanimidade quanto ao modo como deverá prosseguir o trabalho comum, então podemos estar convencidos de que tal estudo está longe ainda de ter seguido a via segura da ciência. É apenas mero tatear" (Kant 6, B VII). Não seria a permanente contenda dos colaboradores de Kant a prova indiscutível, conforme mesmo o critério exposto por Kant, de que a Crítica falhara no intuito de apontar o caminho para a ciência? Pode-se julgar com alguma certeza que, aos olhos do próprio Kant, dificilmente outro fato ou resultado seriam tão eloqüentes do perigo que corria o projeto crítico. Pois é esse mesmo Kant que, tendo concebido a Crítica como o tribunal que deveria pôr fim a toda dissensão no solo da razão, semelhante a um contrato que deveria suprimir a guerra de todos contra todos na metafísica, é levado a dizer: "a filosofia crítica tem de se sentir convencida (...) de que não a aguarda nenhuma mudança", do que se depreende que, no momento, ela não está convencida disso. Com a Declaração, Kant procura demarcar o seu território e pôr a filosofia crítica ao abrigo, não de seus adversários, mas dos seus continuadores; ao proclamar que a Crítica é um sistema acabado, Kant desqualifica como alheio ao projeto crítico todo o empreendimento radical dos discípulos.

Não demora a resposta de Fichte. Em 28 de setembro de 1799, Schelling faz publicar no Allgemeine Literaturzeitung, com o consentimento de Fichte, uma carta que este lhe escreveu sobre a Declaração. Fichte mantém-se fiel, pelo menos em público, ao que antes da Declaração escrevera a Kant: "Meu apreço pelo senhor é tão grande, que não lhe posso levar nada a mal" (1.01.1798). Na resposta de Fichte, não há nenhum traço do furor teutonicus tão comum em seus escritos polêmicos, e que seria plenamente justificável ante a artilharia pesada de Kant (cf. Kant 5, v. 13, p. 548-9). Em relação ao conselho de Kant (a saber, de que Fichte deveria utilizar com proveito seu dom de exposição na CRP), Fichte se diz mais inclinado a seguir outro conselho, que o autor da Crítica lhe dera oito anos antes: caminhar sempre com os próprios pés. A seguir, ressalta o que Kant diz "com amável eqüidade" na Declaração: trata-se não do objeto julgado, mas do sujeito que julga. Já sobre algo referente ao objeto julgado, isto é, a declaração de Kant de que a doutrina da ciência seria mera lógica, Fichte afirma: "Sobre esse ponto estou, como se entende, total- 
mente de acordo com Kant; mas a expressão doutrina da ciência não assinala, segundo a minha linguagem, de modo algum a lógica, mas a filosofia transcendental ou a própria metafísica. Nossa disputa seria assim uma mera disputa de palavras". Já em 1800, Fichte é mais incisivo quanto à Declaração: "Só peço que não rejeitem de antemão e sem exame essa idéia, tão logo ouçam pronunciar as palavras doutrina da ciência e intuição e intuição intelectual (...) - à maneira de Kant, que recentemente se pôs a explicar às pessoas as expressões que elas mesmas utilizam, de tal modo que estas têm de ser consideradas incorretas de qualquer modo que se empreguem" (Fichte 1988, p. 192). Já em suas cartas, o tom é outro. Fichte não exclui inteiramente a possibilidade levantada por Schelling de que a Declaração seria um meio de Kant, preocupado consigo mesmo, se precaver contra alguém acusado de ateísmo: "Pois suficientemente medroso e sofista é o velho, e que ele caiu no descrédito do rei - bem antes e independentemente de mim - é algo que sei com muita certeza". E noutra carta, também a Schelling, escreve: "Estou de fato inteiramente convencido de que a filosofia kantiana, se não deve ser tomada como nós a tomamos, é um absurdo total. Mas, como desculpa para Kant, penso que ele está sendo injusto consigo mesmo, que ele, presentemente, já não conhece nem entende sua própria filosofia, que nunca lhe foi especialmente fluente; quanto à minha, certamente não sabe nada mais do que pegou por alto em uma resenha unilateral" (20.09.1799, Kant 5, v. 13, p. 549 e 550, respectivamente).

É notável, para voltarmos à carta publicada por Schelling, que Fichte afirme, apesar de todas as voltas, que Kant já está superado: "Em regra, caro Schelling, enquanto os defensores da metafísica pré-kantiana ainda não pararam de dizer a Kant que ele se ocupa com sutilezas infrutíferas, Kant nos diz a mesma coisa; em regra, enquanto aqueles asseguram contra Kant que a metafísica deles não se apresenta ainda danificada, mas perfeita e imutável para todos os tempos, Kant assegura, contra nós, a mesma coisa sobre a dele”. Em poucas palavras, Kant é pré-fichtiano. Afinal, esse é também, como mostra a recensão sobre Buhle, o juízo da época - "Kant é o primeiro mestre da filosofia-transcendental; mas o primeiro filósofo-transcendental mesmo é indiscutivelmente Fichte". Com o presente obscurecido, não resta a Kant senão o futuro. Assim, no crepúsculo da vida, profetiza uma nova aurora para a sua filosofia: "Cheguei um século mais cedo com os meus escritos; somente em cem anos serei corretamente compreendido e, então, de novo meus livros serão estudados e reconhecidos" (id.ibid., p. 549). 
Para além das motivações pessoais, de um caráter que "não pode suportar bem nenhuma contradição" (nas palavras de Pörschke sobre Kant, Vorländer 12, p. 258). Kant visa com a Declaração demarcar o seu próprio território. Se antes o escrito apócrifo de Fichte fora tomado por uma obra de Kant, agora é o momento em que a filosofia kantiana é que começa em parte a ser confundida com a de Fichte, e a Declaração não é senão o decreto que, por força da autoridade, tenta distinguir e separar a essência da filosofia crítica do seu posterior desenvolvimento. De um ponto de vista biográfico, poderíamos apontar esse desenvolvimento como uma conseqüência natural da necessidade que alguns discípulos sentiram em trilhar seus próprios caminhos. Mas essa posição, do ponto de vista estritamente filosófico, passa ao largo do problema. Assim, seria certamente possível se ater à generalidade da filosofia crítica: uma filosofia que tem como primeiro motor a liberdade do sujeito e que assinala a maioridade como o exercício autônomo da razão, contra qualquer tutela - essa filosofia parece por essência se dissociar da adesão a um sistema cartorialmente declarado como verdadeiro e acabado. Na filosofia, a tradução dessa autonomia e maioridade aparece nas célebres palavras finais da CRP - "a filosofia é uma simples idéia de uma ciência possível, que em parte alguma é dada in concreto (...). Até então não se pode aprender nenhuma filosofia; pois onde está ela? Quem a possui? Pelo que se pode conhecê-la? Pode-se apenas aprender a filosofar" (Kant 6, B 866); não constitui isso, mais do que um convite, o dever mesmo de não encontrar nenhum ponto de repouso em nenhuma filosofia historicamente dada e condicionada, como também o é o sistema kantiano do ponto de vista subjetivo (de quem aprende)? Kant toma como exemplo um mero discípulo que aprendeu a filosofia de Wolff: desta, conhece todos os princípios e divisões, assim como o inteiro edifício teórico. Mas então possui apenas um conhecimento histórico do sistema wolffiano e sabe apenas o que lhe foi dado: "Contestailhe uma definição, e então ele não sabe onde buscar outra. Formou-se (bildete) segundo uma razão alheia, mas a faculdade de imitar (nachbildende) não é a faculdade de produção, isto é, o conhecimento não resultou nele $d a$ razão e embora seja, sem dúvida, objetivamente um conhecimento racional, é, contudo, subjetivamente, apenas histórico. Compreendeu e reteve bem, isto é, aprendeu, e assim é a cópia em gesso de um homem vivo" (id.ibid., B 864). Esse exemplo do discípulo de Wolff não encerraria em si algo como um imperativo filosófico: não se deixar formar por uma razão alheia? Esse imperativo não significa- 
ria para Fichte desenvolver e aprofundar o criticismo independentemente do mestre? Afinal, Fichte poderia, citando a mera letra da CRP, devolver ao mestre: "Um conhecimento pode assim ser objetivamente filosófico e, contudo, subjetivamente histórico, tal como acontece com a maior parte dos discípulos e com todos aqueles que não vêem nunca mais longe do que a escola e permanecem toda a vida discípulos" (Kant 6, B 865), ou ainda: "é por isso que todas as ciências, porque concebidas do ponto de vista de certo interesse geral, têm de ser explicadas e definidas não segundo a descrição do seu criador, mas segundo a idéia delas, que se encontra fundada na própria razão" (id.ibid., B 862).

Se essa generalidade do motivo, ao implicar a ausência de um alvo preciso e determinado, eventualmente não se mostre suficiente para explicar o processo evolutivo do criticismo, talvez seja necessário então nos atermos ao caráter, à primeira vista mais determinado, de alguns aspectos doutrinais da filosofia crítica. Tomemos, por exemplo, as palavras de Kant, segundo as quais o esquematismo seria "uma arte oculta nas profundezas da alma humana". Dificilmente se compreenderá o alcance dessa sugestão, se não lembrarmos que Fichte localiza a porta de entrada para o seu sistema precisamente nesse meio da Crítica, que é o esquematismo. Não é esse um modo de levar a cabo o convite final da CRP: fazer do atalho crítico uma estrada real (id. ibid., B 884)? Afinal, a própria crítica kantiana se apresenta como propedêutica à ciência, mas não o próprio sistema ou ciência: "A filosofia da razão pura é ou propedêutica (exercício preliminar) (...) e se chama crítica, ou em segundo lugar o sistema da razão pura (ciência) (...) e se chama metafísica" (id.ibid., B 869; cf. também B XLIII).

Assim, de diversos modos a crítica se apresenta como ponto de partida, e no entanto Kant, na Declaração, diz:

1. a doutrina da ciência de Fichte é um sistema inteiramente insustentável, pois é mera lógica, e, como lógica pura, que apenas abstrai do conteúdo, não pode extrair de si um objeto real.

2. "para mim é incompreensível a pretensão de me imputar este intuito: eu quis fornecer meramente uma propedêutica para a filosofia transcendental, não o próprio sistema dessa filosofia" (em flagrante dissonância com o texto da Crítica).

3. A Crítica e sua doutrina da sensibilidade devem ser entendidas literalmente. 
Esses três ítens, em aparente dispersão, na verdade se ligam intimamente. Limitemo-nos aqui a algumas indicações. Que significa, em primeiro lugar, aceitar a "Estética transcendental" literalmente (acima, item número três)? A resposta de Kant visa a esta observação do autor da resenha sobre Buhle: "Deveríamos acreditar enfim que um homem que, juntamente com todos os kantianos, se diz contra a coisa em si, possa partir de um ser na mente (Gemüt) e com a mente, portanto de um substrato, logo, efetivamente de uma coisa em si, em vez de reconhecer uma atividade, uma ação como princípio originário da filosofia?" E, diz o resenhista, se Buhle, em seu Projeto da filosofia transcendental, assim oscila, é porque o próprio Kant "oscila entre o transcendental e o empírico e muito frequientemente sai do aspecto crítico e cai em um dogmático" (Kant 5, v. 13, p. 547) Nesse contexto, aceitar a "Estética" ao pé da letra significa assumir que a sensibilidade é mera receptividade: o objeto empírico, como uma multiplicidade de relações indeterminadas (isto é, como múltiplo sensível dado numa intuição que possui uma unidade prévia a toda atividade) é, numa primeira instância, dado ao sujeito pela ação de algo, em si mesmo desconhecido, sobre a sensibilidade, e não é produzido pela atividade transcendental. Por sua vez, isso significa que a atividade objetivante do sujeito é essencialmente a atividade de determinação da legalidade universal do objeto empírico dado; em outras palavras, a atividade do sujeito é indissolúvel da atividade de síntese do que é dado, segundo leis necessárias - os conceitos puros -, mas de modo algum é atividade de gênese do próprio dado. Segue-se que toda atividade transcendental, indissolúvel do conceito puro, quando abstraída de toda matéria sensível ou da referência à sensibilidade, tenha de ser vazia: mera forma lógica que é, assim, do âmbito da lógica pura, incapaz de, por si só, passar para o nível do objeto (acima, primeiro item). E se, no processo de construção do objeto de experiência a partir do objeto empírico dado, a atividade transcendental é indissolúvel do conceito, então ela não pode ser remetida a uma atividade anterior que seria o fundamento dessas categorias, como se estas fossem a cristalização de uma atividade criadora. Desse modo, o conjunto das categorias recobre em toda a sua extensão o domínio da atividade transcendental quanto ao processo de objetivação. Ora, se a "Estética" é tomada literalmente, se a atividade transcendental é, por conseqüência, essencialmente sintética, indissolúvel das categorias, então a Crítica pode se apresentar já como um sistema, no sentido de ter apresentado a totalidade das condições transcendentais e enunciado "de maneira completa e sistemática todos os atos simples da razão", "não só descrevendo o contorno dos seus limites, mas também toda a sua estrutura in- 
terna" (como indica Kant nos "Prefácios" da primeira e da segunda edição da CRP, A XIV e B XXII-III, respectivamente). Nessa exata medida, a Crítica não é mera propedêutica (item número dois), tal como Fichte e Beck entendiam, por exemplo, a "Estética": um mero recurso pedagógico que, como ponto de partida provisório, não transcendental, conduziria o leitor ao ponto de vista transcendental e ao cerne do criticismo na "Lógica transcendental", momento esse que tornaria superado o ponto de vista inicial da "Estética" (lembremo-nos mais uma vez da história da porta de acesso que se encontraria, segundo Fichte, no meio da Crítica). Certamente, em outro significado, a crítica é propedêutica no que ela contém da totalidade dos princípios (os "atos simples da razão") que, no entanto, carecem ser prolongados no sistema da razão pura e na metafísica. Daí a afirmação de que a dedução metafísica só apresenta os conceitos primitivos, não os derivados, já que o intuito da Crítica é oferecer não "a completude do sistema, mas tão somente os princípios para um sistema" (Kant 6, B 108); daí a promessa de Kant, nos dois Prefácios da CRP, de realizar a metafísica e também o convite, no final da obra, de que se faça do atalho crítico uma via real. Sem dúvida, em razão da diversidade de planos que Kant apresentou ao longo do tempo, é difícil estabelecer rigidamente o movimento de passagem da Crítica como propedêutica à metafísica (seja a da natureza, seja a dos costumes; cf. Vleeschauwer 11, p. 557-63.). Entretanto, nesse fluxo se pode perceber uma orientação geral. Dado o sentido kantiano de propedêutica, realizar a Crítica como ciência ou sistema é promover a análise completa dos conceitos primitivos e, segundo um movimento "de cima para baixo" (que vai dos princípios mais altos, puros, tais como expostos na Crítica, para níveis mais baixos, de maior determinação empírica), constituir a metafísica (metafísica qua determinação a priori por puros conceitos do elemento empírico em sua generalidade máxima - como a questão do movimento na metafísica da natureza -, sem que haja, portanto, a intervenção de uma intuição empírica particular) e finalmente fazer a passagem para o nível empírico de uma matéria que não é em si mesma construída pela atividade do sujeito (cf. Rousset 9, p. 245-63). Assim, ao mesmo tempo que escarnece da "ridícula avidez de renovação e originalidade" dos filósofos críticos infiéis, Kant anuncia que emprega suas últimas forças para concluir o trabalho crítico e preencher outras faltas: "a passagem [Übergang] dos "Princípios metafísicos da ciência da natureza para a física", como uma parte própria da philosophia naturalis, que não pode faltar no sistema" (a Kiesewetter, 19.10.1798). É aproximadamente nesse sentido que Kant esperava que seus discípulos completassem a tarefa crítica (id.ibid., "Prefácio" da 
primeira edição, A XXI), e, diante do projeto comum a eles (em que pese a indeterminação de toda generalização), a saber, encontrar uma unidade fundamental para além das cisões da filosofia kantiana, só resta então a Kant fazer ele mesmo o sistema tal como planejara, lembrando então aos filósofos hipercríticos: "Até que ponto possam coexistir no mesmo ser duas tendências [sensibilidade e atividade] tão contrapostas, é um problema que certamente pode colocar em dificuldades os metafísicos, mas não o filósofo transcendental. Este de forma alguma se propõe a explicar a possibilidade das coisas, mas contenta-se em estabelecer os conhecimentos, a partir dos quais se concebe a possibilidade da possibilidade da experiência [die Möglichkeit der Möglichkeit der Erfahrung]. E visto que a experiência tampouco é possível sem aquela contraposição como sem a sua unidade absoluta, então ele, com perfeita justificação, coloca ambos os conceitos como condições igualmente necessárias da experiência, sem se preocupar ademais com a sua possibilidade de unificação [Vereinbarkeit]" (Opus Postumum citado por Vaihinger 1976, v. 2, p.68). Mas aquele que, ao se preocupar com a possibilidade de superar a cisão, vai acima dos princípios do conhecimento possível, na verdade não se ocupa com nada: "Uma ciência em geral, na qual se abstrai de sua matéria (o objeto de conhecimento), é a lógica pura; e trata-se de um vão girar em círculos com conceitos, quando se pensa, acima destes, uma outra doutrina da ciência mais elevada e universal; essa, porém, não pode conter nada mais do que o científico do conhecimento em geral (a forma deste)" (Kant 5, v. 13, p. 546; grifo nosso) ${ }^{3}$.

A essa altura, ao se ater às linhas mestras da doutrina crítica, parece justo que Kant recuse, para além de um decreto cartorial, o empreendimento fichtiano de aprofundar o criticismo, mas também parece justo que, segundo mesmo a necessidade postulada pela própria Crítica de ir além de toda filosofia subjetivamente histórica, Fichte não encontre repouso na obra de Kant e procure andar com os próprios pés. Ante esse dilema, quem teria razão? Kant, contra Fichte, ao clamar a verdade imutável de seu sistema? Ou, contra Kant, Fichte intérprete do espírito crítico? Sem dúvida, essa questão, que incide em bloco sobre os dois sistemas como um todo, não é passível de uma resposta simples, se é que se pode mesmo encontrar alguma vez em filosofia uma resposta tão redutora e imediata a uma questão de tamanha amplitude. No entanto, é assim que procede Kant ao declarar insustentável a Doutrina da ciência; é assim que faz Fichte, quando dá a entender, nas linhas citadas do Programa da doutrina da ciência, que insustentável mesmo seria a declaração de Kant, já que este teria rejeitado sem exame prévio a Doutrina da ciência, ou ainda quando diz que a filosofia 
kantiana, se não for compreendida como ele a compreende, é um absurdo total. Aceitando, então, o problema, nos termos que os dois filósofos impõem, cabe novamente a pergunta: quem teria razão em se arrogar a posse da filosofia transcendental? Sem ir direto à resposta, mas procurando indicar um atalho, poderíamos numa primeira tentativa dizer: ambos, no que têm em comum, frente a frente, palavra contra palavra, a ignorantio elenchi - o desconhecimento do ponto em questão. Primeiramente Kant, que não poderia com pleno direito considerar "a doutrina da ciência de Fichte um sistema inteiramente insustentável". Como se viu, de próprio punho Kant escreve a Fichte que não se ocupou devidamente com a obra que este lhe enviara, e a Tieftrunk (5.04.1798), confessa: a Fundação de toda a doutrina da ciência é "um livro que ele [Fichte] já há muito me enviou, cuja leitura, porém, tive de pôr de lado, porque o achei extenso e interromperia por demais meu trabalho e por ora só o conheço por uma recensão (...). No momento, não tenho o ócio para lidar com esse livro". O fato é que já a partir da recensão mesma, Kant emite, na carta a Tieftrunk, um juízo desfavorável à Doutrina da ciência. Até que ponto uma recensão, por mais fiel que seja, pode dar uma idéia do todo ou ir além da simples exposição mecânica de um sistema? Assim não se "percorre com impetuosidade uma longa série de proposições sem conhecer suas premissas"? Não tem razão Fichte em dizer que Kant o conhece "por alto", a partir de uma resenha "unilateral"?

Mas também de Fichte, embora por outras razões, pode-se dizer algo análogo. Não que ele tivesse conhecido um Kant de segunda mão. O ponto em questão é que, a certa altura, sua leitura se faz a partir da posterior problematização da obra kantiana. É exemplar a esse respeito o que se passa com uma questão capital da filosofia crítica, a coisa em si mesma. Fichte polemiza com os kantianos "ortodoxos", que lhe apontam as passagens iniciais da Introdução e da Estética transcendental da CRP como exemplos de que Kant admite coisas em si mesmas como fundamentos reais dos fenômenos (não como algo meramente pensado pelo sujeito, como entende Fichte): "Isso serão aproximadamente todas as passagens que os adversários podem citar para si. Aqui simplesmente passagem contra passagem, palavras contra palavras e abstraindo-se da idéia do todo, a qual, como pressuponho, esses intérpretes não tinham - pergunto então: se essas passagens não pudessem efetivamente unir-se com as posteriores expressões, repetidas incontáveis vezes, de que não se trata de modo algum da ação [Einwirkung] de um objeto transcendental que se encontra fora de nós, então por que esses intérpretes preferiram sacrificar, em favor das poucas passagens que, segundo eles, ensinam um dogmatismo, as incontáveis 
que ensinam um idealismo transcendental, e não o inverso, isto é, sacrificar as primeiras em favor das últimas?" (Fichte 3, p. 487). A resposta de Fichte é significativa. Sem querer sacrificar unilateralmente as passagens da "Estética", mas procurando outra interpretação que as unifique com as demais, Fichte busca a chave no próprio Kant: "Kant fala nessas passagens de objetos. O que deve significar nele essa expressão, sem dúvida não temos de determinar nada, mas ouvir a própria explicação de Kant sobre isso". Mas quando se trata de ouvir Kant, "passagem contra passagem, palavras contra palavras e abstraindo-se da idéia do todo", Fichte surpreendemente cita passagens da CRP - não segundo o texto de Kant, mas extraídas de Jacobi, numa reprodução que não só é pouco fiel, mas que inverte o sentido do original ${ }^{4}$. Chamando a atenção para esse fato, Vaihinger conclui: "A Crítica da razão pura tornara-se, pois, patentemente estranha a ele [Fichte]" (Vaihinger 10,p.47). No entanto, mais exato talvez seja dizer que, a essa altura, Fichte pensa a Crítica filtrada pelo prisma de Jacobi.

Quem possui, então, a filosofia crítica? Pelo atalho seguido, encontramos uma possível resposta: os dois, na exata medida em que, lançando luz sobre seus próprios sistemas, acabam por projetar sombra sobre o outro. Essa resposta, no limite, não é senão, do ponto de vista histórico (no significado determinado por Kant, isto é, não segundo a relação, seja lá qual for, com os acontecimentos de seu tempo, mas como conhecimento ex datis que assume diversas formas no tempo), um "dai a César o que é de César" e traduz a tarefa do historiador de filosofia que procura dar conta de um sistema filosófico unicamente pelo texto dado e pela articulação de seus momentos: ter como princípio hermenêutico a suficiência do texto filosófico a ser interpretado, sua coerência e sistematicidade; em outras palavras, o que é dito acaba por se subordinar ao modo como se encadeiam os momentos lógicos do texto (uma tarefa que encontra sua razão em "saber apenas o que foi dado", a exemplo do que diz Kant sobre o discípulo wolffiano). Daí que, isoladamente e de um ponto de vista histórico, cada um dos filósofos apresente um certificado de posse autêntico. Nesse sentido, alguns comentadores de Kant, como Vaihinger, Erich Adickes e Bernard Rousset, propõem-se a dar conta da filosofia kantiana e de suas conhecidas dificuldades, independentemente das interpretações que, pelo prisma dos epígonos, apontam, se não a contradição, pelo menos a insuficiência de um ponto de vista supostamente parcial - no caso, o do próprio Kant (decerto, esses comentadores possuem abordagens diferentes e só com alguma violência se poderia encaixá-los no mesmo figurino da leitura histórico-estrutural; Adickes, por exemplo, recorre a um viés psicológico para explicar as supostas ambigüi- 
dades do texto kantiano, mas essa explicação começa onde havia terminado antes a explicação pelo texto; encontrando por esse caminho uma aporia, Adickes tenta "racionalizá-la". Mas o básico é que todos esses intérpretes procuram a determinação do sistema kantiano primeira e essencialmente pela articulação dos momentos do texto). Escutemos Adickes, que na década de vinte afirma: desde Maimon, Beck e Fichte "se quis torná-lo [Kant] mais conseqüente do que ele efetivamente foi e mesmo quis ser. (...) E Kant, tornado assim conseqüente pelo artifício e pela força, tinha então de ser aceito sem contradição, para servir como testemunha capital de uma espécie de idealismo que não era o seu. (...) Um tal procedimento é exatamente o contrário da compreensão histórica. Ele era compreensível na última década do século, quando a escola de Kant se impusera vitoriosamente tanto contra a escola de Leibniz-Wolff como contra a da filosofia popular. A partir daí começou um processo historicamente necessário de divisão, em cujo curso cada um dos discípulos, que se desenvolveram de modo autônomo, reivindicava para si a autêntica crença kantiana (...). Hoje, o tempo de um procedimento puramente histórico me parece ser mais válido" (Adickes 1, p. 1-2). Bernard Rousset insiste no mesmo ponto quarenta anos depois, o que mostra o vigor (alguns talvez dissessem teimosia) do adversário: "Se procura ainda seus fundamentos e suas regras, a história da filosofia tem suas convenções e suas tradições: assim, todo intérprete de Kant deve, há cento e cinqüenta anos, denunciar as contradições e ambigüidades da CRP; há um século, sente-se obrigado a explicar a partir delas a aparição das diversas filosofias pós-kantianas e tomar o partido dessas, mesmo quando se opõem ao projeto, às afirmações e aos interditos críticos" (Rousset 9, p. 9). O essencial, aqui, não é destacar o resultado alcançado por esses comentadores, mas sim o princípio de que partiram: a recusa, embora nem sempre explícita em cada estudo em particular, mas sempre subjacente na orientação geral, de considerar Kant como mero ponto de partida de Fichte ou de outro "epígono". Em outras palavras, apontam no lado oposto (Gegenseit; assim escreve Adickes) o desconhecimento da autêntica filosofia kantiana e sua distorção por um erro, já de início, de perspectiva. Não seria de esperar uma réplica? De fato, do outro lado se ouve um intérprete como Philonenko dizer: "B. Rousset quer refutar a interpretação idealista que Fichte deu de Kant. É o que ao mesmo tempo há de mais exterior à sua proposta - pode-se ler Kant sem Fichte - e também de mais frágil. De Fichte, B. Rousset faz uma idéia mais do que tradicional (...). Coisa inútil, vã e falsa" (Philonenko 7, p. 160). Rousset, acreditando em Hegel, imaginaria que Fichte teria representado contra Schelling o princípio da subjetividade: “(...) se 
se considera o primeiro Fichte, sua doutrina não é de modo algum idealista e não nega de modo algum a coisa em si, como parece acreditar B. Rousset ao citar repetidas vezes a carta de Kant a Tieftrunk a respeito da Doutrina da ciência, que o autor da Crítica certamente não lera, com exceção da primeira página" (Philonenko 7,p. 176). Em outras palavras, o que Philonenko faz não é senão denunciar o desconhecimento da questão: Rousset, em última análise, ignora Fichte, que serviria então, segundo Philonenko, de mero "repoussoir". Não é difícil perceber que a história, aqui, se repete. Reencontramos agora nos intérpretes o que tínhamos encontrado na origem: a imputação ao adversário, de parte a parte, da ignorantio elenchi. Isso leva a uma espécie de "antinomia", em que cada um dos intérpretes defende a autenticidade de sua posição denunciando a ignorância do lado oposto, nas seguintes formulações possíveis: "A interpretação do Kant autêntico não pode passar pela perspectiva de Fichte intérprete de Kant" e "a interpretação do Fichte autêntico não pode passar pela perspectiva de Kant intérprete de Fichte".

O próprio Philonenko indica o que parece ser um novo caminho que supere a dificuldade. Seria necessário interpretar a doutrina kantiana (Philonenko se refere à doutrina da coisa em si) mais da perspectiva prática do que da teórica, do mesmo modo que "seria necessário interpretar o idealismo fichtiano de modo inteiramente diferente do que o faz B. Rousset" (id. ibid.). Mas vista mais de perto, essa alternativa não é nova e não implica mudança alguma na resposta dada inicialmente. Apenas acentua a necessidade de não simplificarmos nem a filosofia de Kant nem a de Fichte, isto é, de não projetar sombra sobre um, quando se ilumina o outro. Mais uma vez, desse ponto de vista histórico, ambos seriam legítimos proprietários da filosofia, mas em seus respectivos domínios, e a "antinomia" da interpretação surgiria apenas quando se contrapõem as duas perspectivas.

Mas seria esse o único caminho possível? Não seria possível ir além do mero confronto entre a filosofia de Kant e a de Fichte, da comparação entre dois sistemas que, por essa via, seriam em última análise incomensuráveis? Certamente, é um momento essencial revelar a pertinência e legitimidade de temas e conceitos na economia de cada um dos sistemas filosóficos. Tomemos o próprio Kant como exemplo. É notável, relativamente a um ponto específico da filosofia crítica, que um intérprete como Rousset encontre, segundo o texto kantiano, legitimidade para o conceito da coisa em si mesma como fundamento real do fenômeno, sobretudo quando é quase moeda corrente a interpretação contrária, de inspiração fichtiana, concebendo, assim, o projeto kantiano em sua 
totalidade como uma doutrina da objetividade, e mais uma vez em dissonância com uma linha de interpretação que se aproxima muito da perspectiva "hipercrítica" (Vleeschauwer, em seu comentário sobre a "Dedução transcendental", é um exemplo bastante significativo). É essencial, então, que a interpretação mais rigorosa busque mostrar que entre o criticismo e a Doutrina da ciência não há uma linha reta e contínua, como se finalmente o atalho crítico tivesse se tornado a via real com Fichte. Com isso certamente ganha não apenas o intérprete de Kant, no que pode alcançar em maior fidelidade ao original, mas ganha também o intérprete da obra fichtiana, que pode deixar de ser considerada, como Philonenko parece concebê-la, uma "correção" à filosofia kantiana. Pois é isso que esse intérprete dá a entender quando diz que, se Rousset não resolve o problema da dialética da consciência de si e da consciência do objeto, é porque Kant mesmo não o faz - o Kant "que nenhum fichtiano jamais se resolverá a considerar como infalível" (Philonenko 7, p. 176; grifo nosso). Mas essa perspectiva histórica é a única que aqui nos resta? Não seria possível ir além da mera comparação de sistemas (que do ponto de vista histórico-estrutural foram tornados incomensuráveis) e apontar então o projeto filosófico - o ponto de intersecção, anterior à própria cristalização em sistema, em que ocorre a avaliação, a reflexão, a discussão e, enfim, o julgar e o medir que levam à forma historicamente assumida pela filosofia e à distinção entre os sistemas? Não é esse propriamente o momento crítico (em toda a extensão do significado que crítica, etimologicamente, encerra em si: crise, critério, discernimento, separação), que leva à reflexão sobre os conceitos dados previamente em um sistema, i.e., a apropriação e o remanejamento de conceitos à luz de um projeto próprio que se desenvolve? (por esse prisma parece significativo que Fichte, na Segunda introdução à doutrina da ciência, ao reivindicar para si a autêntica interpretação da Crítica contra o kantismo dos kantianos quanto ao verdadeiro papel da coisa em si, sinta a necessidade de abandonar a linguagem kantiana em favor de sua própria ${ }^{5}$, como se a filosofia de Kant possuísse uma figura tal que não pudesse ser encaixada perfeitamente, sem alteração de sua forma original, no sistema que Fichte desenha). Assim, desde que, advertidos por alguns intérpretes, já não se veja uma linearidade entre Kant e Fichte, a atitude de Fichte, menos do que uma interpretação infiel da CRP, não indicaria a releitura de Kant à luz de um projeto que não se encontra dado em Kant, mas se desenvolve a partir da sua problematização e reflexão, e mesmo à luz de outros problemas?

Essas perguntas, evidentemente, só têm validade como hipóteses metodológicas a serem comprovadas pelo resultado a que levam, e nesse sentido 
têm tanta validade quanto a hipótese do historiador de filosofia que, na leitura de um texto filosófico, tem como parti pris teórico a suficiência e sistematicidade do texto a ser investigado, o que certamente não é, por indução do resultado de várias leituras anteriores, garantia alguma de outro resultado favorável. Talvez então, por essa outra via, nos aproximemos do terreno movediço que não pode ter um autêntico proprietário e possamos compreender, na relação entre Kant e Fichte, por que os filósofos não são comentadores nem fazem o que tentamos fazer - história da filosofia; nós, ou seja, "aqueles que não vêem nunca mais longe do que a escola e permanecem toda a vida discípulos".

\begin{abstract}
This paper deals with the Declaration of Fichte's Doctrine of Science, Kant's objection to Fichte published in 1799. The first part of the text tries to determine the historical horizont of the Declaration by presenting some biographical data about Kant's relations with disciples (especially with Fichte). In the second part, some reasons are pointed out to justify, from the point of view of the Critique of Pure Reason, Kant's defense against Fichte's interpretation of that work. Finally, this controversy, which involves a comparison between Kant's philosophy and Fichte's, leads us to some questions about the pertinence of the method used by some authors to interpretate the relation between that two philosophical systems.

Key-words: pure logic - propædeutics - system - transcendental philosophy - doctrine of
\end{abstract} science

\title{
Notas
}

1. Os dados a seguir, sobretudo deste e do parágrafo seguinte, foram extraídos (com pequenos acréscimos meus tirados da correspondência de Kant) de Voländer 1977, p. 260-264.

2. Fichte acredita, em sua resposta à Declaração, que Kant esteja se referindo à Segunda introdução à doutrina da ciência, de 1797.

3. Observação feita por Kant entre maio e agosto de 1799. 
4. Compare-se o texto da CRP, A 105, bem como o comentário de Riehl 8, p. 384, com a versão de Jacobi assumida por Fichte na Segunda introdução à doutrina da ciência (cf. Fichte 3, p. 487).

5. Sobre a coisa em si mesma como um pensamento necessário, diz Fichte: "Essa é a opinião de Kant e a da Doutrina da Ciência"; e para defender esse ponto, Fichte observa: "Para isso me servirei de minha linguagem [Sprachgebrauch] e não da kantiana, porque naturalmente domino mais a primeira do que a última" (Fichte 3, p. 489).

\section{Referências bibliográficas}

1. ADICKES, E. Kant und das Ding an Sich. Berlim, Pan Verlag Rolf Heise, 1924.

2. FICHTE, J.G. "O Programa da Doutrina-da-Ciência (1800)”. Em: A 'Doutrina-da-Ciência de 1794' e outros escritos. Trad. Rubens Rodrigues Torres Filho. São Paulo, Abril, 1988 (col. "Os Pensadores”).

3. _ "Segunda introdução à doutrina da ciência". Em: Fichtes Werke. Berlim, Walter de Gruyter, 1971, vol. 1.

4. KANT, I. Gesammelte Schriften. Ed. Königlich Preussischen Akademie der Wissenschaften. Berlim, Georg Reimer, 1902, vol. 11.

5. Gesammelte Schriften. $2^{\underline{a}}$ ed. Berlim e Leipzig, Walter de Gruyter, 1922.

6. Kriyik der reinen Vernunft. Ed. Raymond Schmidt. Hamburgo, Felix Meiner, 1971.

7. PHILONENKO, A. Études kantiennes. Paris, Vrin, 1982.

8. RIEHL, A. Der Philosophische Kriticismus. Leipzig, Engelmann, 1876/ 1879/1887, vol. 2 .

9. ROUSSET, B. La doctrine kantienne de l'objectivité. Paris, Vrin, 1967. 
10. VAIHINGER, H. Commentar zu Kants Kritik der Reinen Vernunft. New York e Londres, Garland, 1976, vol. 2.

11. VLEESCHAUWER, H.J. de.La Déduction Transcendentale dans l'Oeuvre de Kant. New York e Londres, Garland, 1976, vol. 3.

12. VORLÄNDER, K. Imannuel Kant, Der Mann und das Werk. 2aㅡ. ed. Hamburgo, Felix Meiner, 1977. 